Stephen Bloch-Schulman, ELON UNIVERSITY, sschulman@elon.edu

\author{
Susan Wharton Conkling, BOSTON UNIVERSITY, drc@bu.edu \\ Sherry Lee Linkon, GEORGETOWN UNIVERSITY, Sherry.Linkon@georgetown.edu \\ Karen Manarin, MOUNT ROYAL UNIVERSITY, kmanarin@mtroyal.ca \\ Kathleen Perkins, COLUMBIA COLLEGE CHICAGO, kperkins@colum.edu
}

\title{
Asking Bigger Questions: An Invitation to Further Conversation
}

\begin{abstract}
In this essay, the editors and contributors to this special section on SoTL in the Arts and Humanities argue that given the current climate and context, debates within SoTL about appropriate methodology both lead scholars from their disciplines to reject SoTL and also, more importantly, distract us from more significant questions and challenges. If, instead, SoTL would embrace not only its diversity but also its political potential, then we, as a scholarly community, would be in a position to do more than merely improve students' learning in our own classrooms. We could help to transform higher education. To achieve that, we need a broader conversation and a wider range of studies. We also need to be mindful of and engaged with the political, economic, and ideological forces that are shaping our institutions, our work, and our students' expectations.
\end{abstract}

\section{KEYWORDS}

arts, humanities, methodology, disciplinary perspectives, scholarship of teaching and learning

In the American political tradition, leaders have regularly deployed the jeremiad, a rhetorical tool that involves first chastising the country for the ways in which it has fallen short of its original ideals and then exhorting fellow citizens to renew their commitment to first principles and pledging to lead the way. To conclude this set of articles on teaching and learning in the performing arts and humanities, we offer our own jeremiad of the scholarship of teaching and learning (SoTL). Like many political candidates, we approach this discourse-to use the religious language associated with the jeremiad-as fellow sinners, as critics, maybe even (to be quite grandiose) as prophets. We hope not only to identify some ways that SoTL has fallen short of its original and highest ideals but also to suggest the consequences of that fall and to exhort ourselves and our colleagues to re-embrace the principles that brought so many of us into the SoTL fold.

In the beginning, the scholarship of teaching and learning was envisioned as a discipline-based practice that would accomplish four outcomes: improve higher education by engaging faculty in disciplinary, cross-disciplinary, and systematic analysis of student learning; generate shared knowledge about learning through the publication and presentation of that research; demonstrate that teaching is a scholarly practice by making it visible, amenable to peer review, and tangible; and develop a richer conversation about teaching and learning by bringing faculty together across the disciplines. Early SoTL leaders came from a range of fields, and when the Lee Shulman, Pat Hutchings, and Mary Huber of the 
Carnegie Foundation for the Advancement of Teaching designed the Carnegie Scholars Program, which would jump start SoTL in the United States, they planned for both disciplinary and cross-disciplinary conversations, promoting the idea that faculty bring disciplinary expertise to the field but should also see their work as part of a broader conversation. New SoTL researchers were encouraged to draw on theories and methods from their disciplines and to consider diverse strategies and theories from their colleagues. One of the first books on scholarship of teaching and learning explored "disciplinary styles," and in that book, Mary Huber and Sherwyn Morreale suggest that SoTL benefits from this diversity, in part because its practitioners learn from each other in what they describe as an "intellectual trading zone" (19). With less overt attention to disciplinary diversity, Hutchings suggested that SoTL researchers could and should ask varied questions. She mapped out four genres of SoTL inquiry, including not only "does it work?" but also questions about how students learn, explorations of new possibilities, and the development of theories of learning.

But even from the beginning, SoTL had a conflicted relationship with its own intellectual diversity. Several of us were in the second class of Carnegie Scholars, and despite the encouragement to shape our work based on our disciplines' approaches, we were regularly harangued by colleagues from more empirical fields, told that our methods were insufficient or invalid. The assumptions that lay beneath those statements have, over time, emerged as shaping forces in the field. While some journals in the field encourage a wide range of approaches, others state that they publish only "data-driven studies." Journal editors may not intend to exclude arts and humanities research, but because scholars from our fields don't think of our work as "data-driven," we read such statements as signals that our studies would not meet the criteria. Even something as seemingly minor as citation formats reflects the dominance of social science. Most SoTL journals, including this one, use APA format for citations, a model that reflects not just the conventions but also the modes of thinking rooted in psychology.

Many SoTL scholars have been thoughtful and critical about these methodological concerns. In recent years, a number of articles, studies, and conference panels have examined the tensions between the humanities and the social sciences. ${ }^{1}$ Indeed, across the field most seem to agree that we should both respect a wide range of methods and encourage the use of mixed methods. Nonetheless, a significant portion of published SoTL uses experimental or quasi-experimental designs and statistical analysis to examine the effectiveness of a specific pedagogical intervention, often using course quizzes, test, or grades as indicators or proxies of student growth. In a recent article in the Canadian Journal of Scholarship of Teaching and Learning, Ada S. Jaarsma reviews prominent definitions of SoTL and concludes that it "aligns closely with empiricist assumptions about rigour and evidence" and that in this formulation, "'learning' is understood in and through the expectations that it will improve through the empirical methods of observation and measurement" (2). The publication record of SoTL makes, Jaarsma writes, "an implicit claim that scholarly research is empirical research" (2).

The empirical emphasis that Jaarsma identifies has at least two problematic consequences. First, it discourages scholars from the arts and humanities from engaging in SoTL. Too many faculty from these fields either assume that what they do simply isn't scholarship of teaching and learning or feel marginalized within the field. This is true even though many of the leading theorists and organizers of SoTL_-Pat Hutchings, Randy Bass, Anthony Ciccone, David Pace, to name a few-come from the humanities. They are respected as leaders, yet their disciplinary peers within SoTL have regularly found themselves having to justify the value of their research and to do so in social scientific terms. In one case, for example, a literary scholar leading a workshop to explore what humanities-based methods offer to SoTL was shouted down by participants who insisted that only social science approaches backed by 
quantitative data "counted" as SoTL. Others have been challenged by colleagues from psychology and sociology, told that their work "would never get published" because it wasn't sufficiently objective or that their approaches were suspect because they didn't display adequate concern for validity. Wellmeaning colleagues have tried to school us in how to extract quantitative data from qualitative evidence, assuming that the only obstacle we faced in quantifying our research was our limited knowledge of statistical methods. This is not the case. We recognize that statistical calculations can have value, and many of us have, indeed, learned to produce and interpret statistical outcomes related to learning.

Despite the thoughtful dialogue, neither our well-intentioned social science colleagues nor the humanists who have tried to argue for greater mutual understanding and acceptance have succeeded in ending this contretemps. This is because all of us, social scientists and humanists alike, are products of our fields, and our ideas about what constitutes "research" and how best to approach it reflect the cultures of our disciplines. Where many social scientists learn to prioritize proof and objectivity, most scholars in the arts and humanities learn to value process and the complexity of subjectivity. Social scientists are taught to worry about subjectivity, while humanists are taught to be skeptical about claims of objectivity. Instead of asking whether a study has yielded statistically significant evidence, we ask whether it helps us strengthen a theory or notice something new. These contrasts reflect cultural differences that cannot be bridged or resolved simply by encouraging everyone to use mixed methods. The advice we are often given, and the unarticulated assumption of many questions we get, assumes social science as the unquestioned norm. When social scientists engage with arts and humanities faculty from that perspective, expecting that we will justify our work on their terms, we are faced with an impossible choice: incorporate empirical approaches that we have consciously and carefully chosen not to use in order to address colleagues within SoTL or eschew them in an effort to reach colleagues within our fields, for whom empirical models are not simply unfamiliar but often suspect at the cost of becoming silenced or dismissed within SoTL conversations.

In the current climate, in which the sometimes dogmatic norm for SoTL involves social scientific methods, discussion about methodology often feels futile and exasperating, not only because those not using social scientific methods are asked to justify their approaches but to do so in the terms laid down by social scientists. Furthermore, efforts to define SoTL in terms of "appropriate" methodology narrowly limit its reach, both for practitioners and readers. If SoTL is to engage faculty across the disciplinary spectrum, it must embrace all kinds of research, including focused, controlled studies that yield statistical analyses and projects that tell significant stories about student learning and that emphasize interpretation, process, creativity, and theory. SoTL would be more inclusive, more interesting, and more significant if, rather than attempting to enforce methodological conformity, we recommitted to the original ideal of disciplinary diversity and exchange.

But this debate presents a second and even more significant problem: to spend our time establishing and defending methodological criteria distracts us from more significant challenges and issues that demand our attention. Many of us, across the disciplines, pursued SoTL because we wanted to make a difference in higher education. Our research has been driven by passion for our students, our disciplines, and our profession. For some, improving the quality of higher education serves a larger social, political, and even moral vision: by preparing students for creative, strategic engagement with the world, higher education could contribute to the development of a more just and capacious society.

Methods matter, of course, and we should discuss them and compare them, show their limits and highlight their different values from a stance that does not assume the hegemony of social science. We must do so while engaging with broader discussions of higher education. In the era of neoliberalism, 
which privileges the interests and approaches of the free market and private business, students have been re-imagined as customers and learning as a commodity. Many policy makers, voters, families, and students have come to define education primarily in terms of acquiring skills for the workplace, and they judge educational effectiveness based on job placement and standardized tests. When we promote a model of research that valorizes controlled studies of whether specific interventions yield statisticallysignificant increases in test scores or grades, we-perhaps inadvertently-enact a vision of education that reduces learning to a mechanical system for producing specific, concrete outcomes that ignores the circumstances of our students' lives, institutional and community conditions, and the broader contemporary culture. Such approaches can decontextualize teaching and learning, but they also define modest change as the most desirable, or perhaps as the only achievable, outcome of our research. Worse, they can inadvertently support the de-professionalization of higher education by suggesting that teaching can be reduced to formulae and standardized methods. Jaarsma suggests that we have been too willing to define learning as that which can be "empirically measured" (4). Further, she writes, SoTL's emphasis on assessing what works "resonates directly with neoliberal demands of transparency and accountability. As a means for securing accountability in higher education, SoTL research reassures students, administrators and the public that educators are accountable for efficiency and efficacy" (5). As a field, SoTL has so much more to offer, including insights and analyses that defy empirical measurement and enable resistance to external pressures while also providing intellectual resources for inventing the universities of the future.

If we want to improve not only our own students' learning but also higher education more broadly, then SoTL should return to its roots, to the initial goals of improving higher education and demonstrating that teaching is serious scholarly work that has implications both within and across our classrooms, institutions, and disciplines. We should be asking how SoTL can not only help us understand how students learn in specific courses but also what theories and approaches should guide the future of higher education, and we should raise these questions even when we debate methodologies. To address this broader and more complex question, SoTL scholars must pursue questions that uncover, articulate, and interrogate learning in a wider range of ways and spaces.

To do that, we believe, SoTL scholars--ourselves included--must engage more fully with bigger and more difficult questions. In the inaugural issue of this journal, Carolyn Kreber argued for this "broader vision SoTL ... that applies across disciplines, and where endeavors aimed at improving learning and creating a better world within which to learn and to teach, are nested within the larger concern for creating a better world" (13). SoTL will always include "does it work" studies of specific pedagogical strategies, but it should put more emphasis on studies that pose questions about the processes and conditions of learning, about the way learning is shaped by (and often located in) students' lives outside of the classroom, about the nature of critical engagement and performative knowledge, about equity and inclusion. We believe in the value of this kind of SoTL not only because it reflects our disciplinary practices and mindsets (though it does), and not simply because it yields insights that we find useful and persuasive (though it does), but because we want to develop SoTL work that will generate critical and creative discussions among faculty and students. Those discussions will not necessarily produce measurable or replicable proof that specific pedagogical strategies work. Rather, they will challenge us to deepen and complicate our understanding of the practices of teaching, the processes of learning, and the purposes of education.

This kind of scholarly inquiry is at once an intellectual and a political act. Through such work, we resist neoliberal discourses that define knowledge in instrumentalist, economic terms and that 
demand that faculty be accountable to external bodies instead of focusing on student development and engagement. Rather than accepting - albeit inadvertently -- the limiting expectations of neoliberalism, SoTL should offer a more complex and challenging vision of education. We can do this through inquiry into learning and teaching that attends to the whole person, treating students not as objects but as people with their own desires, perspectives, and experiences. By examining the ways that learning extends beyond the classroom, course, or discipline, such work would identify habits of inquiry, creativity, analysis, and reflection that help students develop agency, flexibility, and the ability and inclination to learn and grow throughout their lives. By demonstrating the insights available in careful analysis of varied scenes of learning and by developing richer ways of capturing students in the act of developing and deploying knowledge, SoTL can both suggest what works in long-standing models of schooling and envision what could be possible if we re-imagined higher education.

Higher education has been increasingly criticized as ineffective in preparing graduates for the workplace and as economically unsustainable. SoTL can help faculty respond to both of these critiques. Research that traces, represents, and analyzes student learning by looking not only at specific concepts or skills but also at habits of mind and dispositions such as adaptability, tolerance for ambiguity, and engagement can help us demonstrate the broader meaning and value of education. To develop this kind of knowledge, we must look beyond specific pedagogical interventions. These broader outcomes neither originate nor make themselves visible in specific courses, and often they occur outside of the classroom altogether. We need to expand the scope of our research if we want to push back against the instrumentalization of higher education.

The problem of economic inefficiency is more challenging, in part because it is not really based in the way universities organize teaching and learning. As Benjamin Ginsburg argued in his 2011 book The Fall of the Faculty: The Rise of the All-Administrative University and Why It Matters, and as a number of other studies have documented, the economic challenges are not created by, or at least not primarily created by, the cost of teaching. As SoTL scholars, our dedication to teaching and learning can lead us to dismiss concerns about the rising cost of higher education (including questions about who can or should attend college) as distractions or to resist them as undermining the human connections that many of us see as essential for learning. At the same time, we cannot ignore the efficiency problem, because administrators and external policy makers hope to solve it by changing the conditions of our work. Administrators around the world are turning to adjuncts, MOOCs, and competency-based credits as possible solutions. We can respond productively by engaging in research that not only demonstrates the value of good teaching but also explores ways of making alternative approaches work well for students.

To do this, we will need to explore a different and broader set of questions. What does "learning" mean within our various disciplines? How can we prepare students not only to pursue their own interests but also to serve others? What conditions best facilitate learning as a community practice? How can we nurture creativity and passion, and how can we tap into the pleasures of learning and knowing? We need to consider how students develop and demonstrate competency in the kind of analytical and exploratory thinking involved in philosophy or the contextualized reading and analysis of historical, literary, and cultural studies. We should explore the conditions and processes that facilitate studio-based learning, which combines scaffolding and coaching from faculty with peer teaching and iterative practice. We need to capture and analyze how students learn and are transformed outside of class, by producing campus newspapers, organizing volunteer projects, singing in a cappella groups, and competing in sports. To do this kind of research, we will need to deploy a wide range of methods, 
including the exploratory, representational, and interpretive tools rooted in the arts and humanities as well as the observational, experimental, and quantitative approaches rooted in the social sciences. Put differently, diversifying our methodologies matters not for the sake of defining the field or policing each other's work, but because it allows us to pursue bigger questions. If SoTL will return to its original vision and embrace not only its true diversity but also its political potential, then we, as a scholarly community, can do more than improve students' learning in our own classrooms. We can help to transform higher education. To achieve that, we need a broader conversation and a wider range of studies. We also need to think more broadly about education, to be mindful of and engaged with the political, economic, and ideological debates that are shaping our institutions, our work, and our students' expectations. We invite our SoTL colleagues from across the disciplines, from varied settings, and in diverse roles to join us in this conversation.

Stephen Bloch-Schulman, Associate Professor of Philosophy, works at the intersection of political theory and the scholarship of teaching and learning.

Susan Wharton Conkling is Professor of Music, Music Education at Boston University, where she teaches graduate and undergraduate courses in conducting, music education methods, and curriculum.

Sherry Lee Linkon is a Professor of English and Director of the Writing Curriculum Initiatives at Georgetown University. Her books include Literary Learning: Teaching in the English Major (Indiana 2011) and Teaching Working Class (Massachusetts 1999). Her SoTL work focuses on strategic course and assignment design, with an emphasis on learning processes.

Karen Manarin is Professor of English and General Education at Mount Royal University; recent publications include the coauthored book Critical Reading in Higher Education: Academic Goals and Social Engagement.

Kathleen Perkins is an Associate Professor in the Theatre Department of Columbia College Chicago where she teaches acting and text analysis and coordinates both the BFA in Acting and the Department Assessment Programs. She was a scholar in the second cohort of the Carnegie Academy for the Scholarship of Teaching and Learning (CASTL).

\section{NOTE}

1. See, for example, recent essays by Nancy Chick, Regan Gurung, and Michael K. Potter and Brad Wuetherick. The debate has also been carried on in panels at ISSOTL conferences, and we encounter it regularly in informal interactions with colleagues.

\section{WORKS CITED}

Chick, Nancy L. "'Methodologically Sound' under the 'Big Tent': An Ongoing Conversation." International Journal for the Scholarship of Teaching and Learning Vol. 8: No. 2, Article 1.

Ginsberg, Benjamin. The Fall of the Faculty: The Rise of the All-Administrative University and Why It Matters. Oxford: Oxford University Press, 2011. Print.

Gurung, Regan A.R. "Getting Foxy: Invoking Different Magesteria in the Scholarship of Teaching and Learning." Teaching \& Learning Inquiry: The ISSOTL Journa/Vol. 2, No. 2 (2014): 109-114. Print.

Harding, Sandra G. Feminism and Methodology: Social Science Issues. Bloomington: Indiana University Press, 1987. Print.

Huber, Mary and Sherwyn Morreale, eds. Disciplinary Styles in Scholarship of Teaching and Learning: Exploring Common Ground. Stanford: Stylus, 2002. Print.

Hutchings, Pat. Opening Lines: Approaches to the Scholarship of Teaching and Learning. Menlo Park, CA: Carnegie Foundation for the Advancement of Teaching, 2000. Print. 
Jaarsma, Ada A. "On Being Taught." The Canadian Journal for the Scholarship of Teaching and Learning Vol. 6, No. 2 (2015), Article 6.

Kreber, Carolyn. "The Transformative Potential of the Scholarship of Teaching." Teaching \& Learning Inquiry: The ISSOTL Journal Vol. 1, No. 1 (2013): 5-18.

Potter, Michael K. and Brad Wuetherick. "Who is Represented in the Teaching Commons?: SoTL Through the Lenses of the Arts and Humanities." The Canadian Journal for the Scholarship of Teaching and Learning Vol. 6, No. 2 (2015), Article 2.

(c) (1)

Copyright for the content of articles published in Teaching \& Learning Inquiry resides with the authors, and copyright for the publication layout resides with the journal. These copyright holders have agreed that this article should be available on open access under a Creative Commons Attribution License 4.0 International (https://creativecommons.org/licenses/by/4.0). The only constraint on reproduction and distribution, and the only role for copyright in this domain, should be to give authors control over the integrity of their work and the right to be properly acknowledged and cited, and to cite Teaching \& Learning Inquiry as the original place of publication. Readers are free to share these materials_as long as appropriate credit is given, a link to the license is provided, and any changes are indicated. 